\title{
Vocabulary Size, Phonological Awareness, and Reading
}

\section{Comprehension}

\author{
Yu-cheng Sieh $^{1 *}$ \\ ${ }^{1}$ English Department, Tamkang University, New Taipei City, Taiwan \\ *Yu-cheng Sieh, E-mail: ycsieh@mail.tku.edu.tw
}

\begin{abstract}
The present study aimed to explore the relationship among vocabulary size, Phonological Awareness (PA), and reading comprehension in English learners with low proficiency in Taiwan's higher education. Forty-one university students who had taken the Test of English for International Communication (TOEIC) were recruited, 30 of whom were at a proficiency level much lower than B1 Threshold of the Common European Framework of Reference (CEFR) for Languages. Three PA subtests and a vocabulary size test were administered to all participants individually. Pearson's correlations show that their TOEIC reading scores were correlated with the four measures when all 41 participants were included; however, among the 30 low-proficiency learners, their reading scores were correlated with Elision - one PA measure - and vocabulary size only. When parallel regression analyses were computed against all participants and the low-proficiency subgroup, the four measures altogether explained nearly $64 \%$ of the variance in their TOEIC reading scores in the former but the explained variance dropped drastically to around $40 \%$ in the latter. Among the four measures, vocabulary size was the only significant predictor of reading ability and accounted for the largest variance. Meanwhile, phonological awareness explained additional variance in reading comprehension. While different PA measures did not seem to make a difference to the whole sample, Elision seemed to have explained more variance and served as a better task to assess phonological awareness of the low-proficiency subgroup.
\end{abstract}

\section{Keywords}

university learners, Chinese-L1, low reading ability, phonological awareness

\section{Introduction}

The importance of English can never be underestimated. English is undoubtedly the most widely used language when speakers of different native languages try to communicate with each other. Its status of being a global language has prompted the implementation of several new educational policies in Taiwan's higher education. One of them is the requirement of an English proficiency certificate before students leave school. In other words, before university students graduate, they have to reach a certain English proficiency level-usually up to at least the B1 Threshold level of the Common European 
Framework Reference (CEFR; Council of Europe, 2001) for Languages-in a standardized English proficiency test, such as Test of English as a Foreign Language (TOEFL) or Test of English for International Communication (TOEIC). But meeting this specific requirement is simply not easy for less-skilled learners of English as a Foreign Language (EFL). A survey of local college students reported that up to $32 \%$ of the polled had an English proficiency level similar to that of Grade 9 students (Yu, 2003), which indicates that such learners made no more progress after they graduated from the junior high school.

However, the fact that quite a large number of college students have reading skills just beyond the beginning level had not been acknowledged nationwide until the outcry from such less-skilled learners sounded the alarm. For most of them, obtaining passable foreign language proficiency is not easily achievable within a semester or even a year. Furthermore, the problems they have had with English learning might have started much earlier and are not likely to dissolve within a short period of time. In answer to the outcry, universities have mostly responded by offering English remedial courses in the form of distance learning, in an attempt to get the English low-achievers off the hook so that they can graduate. Nevertheless, while the outcry dies down, the condition remains unchanged and few really benefit.

The present study aimed to explore the relationship among reading comprehension, vocabulary size, and phonological processing skills of the less-skilled English learners in Taiwan's higher education. When some reading research in Taiwan has been mainly concerned about test scores mediated by different teaching methods, they nevertheless overlooked the prerequisite subcomponent skills which underlie the nature of reading in relation to the target language. Such skills are likely to be significant indicators of EFL learners' multifaceted reading difficulties and thus provide pedagogical implications to English remedial education.

\subsection{L2 Reading: An Overview}

L2 (Note 1) reading is in principle qualitatively and quantitatively different from L1 reading. To begin with, L2 learners have had literacy experiences in their L1 when they start learning an L2. When they learn the L2, they do not start the same way L1 learners do, but instead omit the first few years of oral language experience and move straight into the stage of written language. Nevertheless, a comparison in the structure of literacy-related skills between English native speakers and EFL/ESL learners has revealed that spoken language as well as orthographic experiences had a great impact on the development of phonological skills (Cheung, Chen, Lai, Wong, \& Hills, 2001). Some L2 learners consequently exhibit poor reading comprehension, due to a lack of proper backup in the development of their L2 system (Harrison \& Krol, 2007), since phonological processing skills have long been proved to be critical to learning alphabetic languages (Anthony, Williams, McDonald, \& Francis, 2007; Bowey, 2001). Furthermore, L2 literacy research is often informed by L1 literacy studies. The underlying factors which facilitate L1 reading are often found to support L2 learners in their literacy development as well (Masoura \& Gathercole, 2005; Pasquarella, Chen, Lam, Luo, \& Ramirez, 2011; 
Yaghoub-Zadeh, Farnia, \& Geva, 2012). Even though reading is commonly viewed as a complex cognitive activity requiring a simultaneous integration of lower- and higher-level processes, it is perhaps quite feasible to look into the lower-level processes of reading when the focus is on less-skilled L2 learners.

\subsection{Reading and Phonological Awareness}

The lower-level reading process is fundamentally concerned with word recognition or processing (Kintsch \& Rawson, 2005). In order to recognize a written word, language learners, upon the visual input, have to identify orthographic forms and activate the phonological representations either partially or fully because of the close grapheme-phoneme correspondence in alphabetic languages. As soon as the grapheme-phoneme connection is successfully established, learners can continue to locate word meanings in their mental lexicon (Ehri, 2005). Despite the label of lower-level process, the subcomponent skills are prerequisites for reading to become fluent and accurate (Grabe, 2009).

Word recognition, as a result, is crucial to learners with low proficiency (Durgunoglu \& Öney, 2002; Sabatini, Sawaki, Shore, \& Scarborough, 2010). When learners have highly developed subcomponent skills to rapidly convert print to sound, they integrate the low- and high-processes and carry out the complex activity without much difficulty. However, if learners frequently stumble over unfamiliar or unknown words, the shared capacity mechanism is heavily demanded by the low-level process and will eventually become less available for other processes (Hannon, 2012). Phonological awareness, the ability to manipulate and analyze the sound structure of spoken language, is therefore critical to successful word recognition because the ability to phonologically decode the print promotes development in word recognition (Hulslander, Olson, Willcutt, \& Wadsworth, 2010).

A bi-directional relationship has existed between reading and phonological processing ability (Hannon, 2012; Li, McBride-Chang, Wong, \& Shu, 2012). Children who have good reading comprehension are usually found to be equipped with adequate phonological processing skills. Likewise, those who possess good decoding skills are more likely to be efficient readers. Being an enduring reading component, phonological awareness has served as a perquisite and a predictor of reading ability in L1 preschoolers and adults joining Adult Basic Education (ABE) programs (Clark, McRoberts, van Dyke, Shankweiler, \& Braze, 2012). Furthermore, ABE learners who had greater strength in phonological awareness gained more from the intervention, indicating that phonological awareness might contribute to reading skills (Scarborough et al., 2013).

The close association between reading and phonological skills has been observed in EFL learners as well. $\mathrm{Hu}$ (2013) recruited Taiwanese children and conducted a two-year research. It was found that their phonological awareness measured at Grade 3 was significantly correlated with English reading across G3 and G5. In addition, phonological awareness was the only significant predictor of English reading at G5 for these EFL learners. However, phonological awareness only made an indirect contribution to reading comprehension in Japanese adult learners of English (Yoshikawa \& Yamashita, 2014). In the study, both nonword reading and vocabulary significantly contributed to reading 
comprehension and jointly accounted for $18 \%$ of the variance, while phonological awareness significantly accounted for $7 \%$ of nonword reading. Despite its indirect contribution, phonological awareness might have served as a basis for English reading among the Japanese-L1 learners.

\subsection{Reading and Vocabulary Knowledge}

However, proficiency in L2 reading might involve more than word recognition. Vocabulary size, for example, is another significant predictor in predicting reading comprehension. It is commonly agreed that vocabulary plays a crucial role in language development. Grant, Gottardo and Geva (2011) recruited a group of English-L1 and another group of English-L2 school children. Vocabulary knowledge in each group was correlated to their performance in reading comprehension. Similar findings are found in Pasquarella, Gottardo and Grant (2012). In addition, even though both decoding and vocabulary were significant predictors, vocabulary played a stronger role in the prediction of reading comprehension in ESL children (Grant et al., 2011).

The association between vocabulary and reading comprehension is also observed in EFL learners. To a group of Chinese-English children in Hong Kong, their English vocabulary and word reading measured at eight years of age explained the most variance in English reading comprehension assessed at $10(\mathrm{Li}$ et al., 2012). In another group of Japanese university students, only efficiency in accessing lexical meanings emerged as a significant predictor of English reading comprehension (Yamashita, 2013). In addition, the importance of vocabulary size might be further consolidated because vocabulary size has been associated with language proficiency levels indexed by standardized language tests (Milton, Wade, \& Hopkins, 2010). While reading materials for older learners become diverse, a wide variety of vocabularies thus turn out necessary. Research results suggest that vocabulary size measures might serve as a useful indicator to place L2 learners at an appropriate proficiency level (Milton \& Alexiou, 2009).

In light of the literature review, it is hypothesized that, in the present study, the participants' reading comprehension, indexed by their TOEIC reading scores, should be correlated with the their vocabulary size and phonological processing skills. In addition, the participants' vocabulary size and phonological skills should contribute to their TOEIC reading scores. However, changes might happen to the correlational relationships and the variance explained by the measures when the statistical tests are computed respectively against all participants and only less-skilled learners. The present study will explore the following questions.

1. Is reading comprehension of the participants correlated with vocabulary size?

2. Is reading comprehension of the participants correlated with phonological processing abilities?

3. Does the participants' vocabulary size contribute to reading comprehension scores?

4. Do the participants' phonological processing skills contribute to reading comprehension scores? 


\section{Method}

\subsection{Participants}

Forty-one university students who had taken the TOEIC were recruited for the present study. Among them, 30 had a proficiency level equivalent to A2 Waystage of CEFR for Languages (Educational Testing Service, 2010) and were labeled the less-skilled subgroup because they scored lower than 275 $(M=151.0, S D=48.68)$ on the TOEIC reading section. The rest 11 participants were at intermediate level $(n=7)$ or upper-intermediate level $(n=4)$; the mean of their TOEIC reading scores was much higher $(M=360.45, S D=49.62)$. In comparison, the subgroup had a mean less than half of that of the 11 participants.

Among the 30 low-proficiency participants, 14 were female and 16 were male. They came from five different disciplines, including Engineering, Liberal Arts, Business and Management, Foreign Languages and Literatures, and International Studies, in a private university in northern Taiwan. Twenty-two of them were local Taiwanese students, another seven were from Macau or Hong Kong, and one from China. Their mean age at participating in the study was $23.82(S D=4.84)$.

Studying at language departments, the rest 11 participants had a mean age of $21.01(S D=1.05)$. Ten of them were local Taiwanese students and one was from China. There were four male and seven female students.

It is believed that the English low-achievers were adequate participants for the present study because, on the one hand, their intelligence quotients were within the norm at least to be admitted to the university. On the other hand, their deficiencies in English reading should thus be solely attributed to factors underlying the learning of the alphabetic language (Breznitz, 2001).

\subsection{Instruments}

Three PA subtests from the Comprehensive Test of Phonological Processing (CTOPP; Wagner, Torgesen, \& Rashotte, 1999) plus a 14k vocabulary size test (Nation \& Beglar, 2007) were employed in the present study.

Elision (EL)

The 20-item task was to explore whether participants could remove a designated phoneme from a word and form another word. For example, participants heard spoil and repeated it. Next, they were asked to remove /p/ and say the newly-formed word soil. Two other items (Say supermarket without saying super and say name without saying $/ \mathrm{n} /$ ) were used for demonstration and explanation before six practice items were played. Most of the test items are one-syllabic words.

\section{Blending Words (BW)}

The 20-item task was to measure whether participants were able to retain and combine a string of phonemes to form a real word. For example, after participants heard $/ \mathrm{n} /$, , $/$, and $/ \mathrm{m} /$, they had to combine the three phonemes and say the word name. Two other items (relax and wage) were used for explanation, followed by six practice items. The number of phonemes contained in the test items range from two to 10. 


\section{Phoneme Reversal (PR)}

The 18-item task was to examine whether participants could retain and manipulate the sounds of a nonword to form a real word by saying the nonword in reversed order. For example, participants heard /dep/ and had to reverse the sounds to say paid. Another item (Reverse / $/ \mathrm{fit} /$ to say teach) was used for demonstration, followed by four practice items. The number of phonemes contained in the test items range from two to seven.

\section{Vocabulary Size Test}

The 14k Vocab Size Test (Nation \& Beglar, 2007) provides an index of the current receptive vocabulary size of the participants. The test consists of 14 lists of words, each of which contains 10 multiple-choice questions. In each question, a sentence containing the target word in boldface is given, followed by four options. Participants were required to choose one answer which matched the meaning of the target word.

\subsection{Procedures}

As soon as the participants arrived, a consent form and the report of TOEIC scores were collected. They were seated in front of a notebook computer and asked to wear a pair of headphones provided by the researcher. Different from the conventional method, the present study employed a computerized version of the CTOPP subtests. The participants were given six seconds to respond in Elision and Blending Words and 10 seconds in Phoneme Reversal. Their answers were recorded. The Vocab Size Test was conducted last. A print version, rather than an online version, of the vocabulary size test was employed. The participants were told explicitly not to make wild guesses and only had to answer the questions whose target words were known to them. For the words which were unknown to them, they simply put a cross " $X$ " next to the question. All the tasks were administered individually at a study room in the private university.

\subsection{Scoring}

One point was awarded to each question answered correctly in the four measures. Raw scores from all four tasks were used for data analyses. Apart from the researcher, an English native speaker was recruited to be a second rater. When disagreements over scoring occurred, the two raters would listen to the recordings again and reach an agreement.

\section{Result}

As the present study aimed to explore the relationships among phonological awareness, vocabulary size, and reading comprehension in all 41 participants as a mixed-ability group and the subgroup of 30 less-skilled learners as a low reading proficiency group, results of the whole sample of participants and the subgroup are juxtaposed to show similarities or differences, and a shift of patterns. 
Table 1. Means and Standard Deviations of TOEIC Reading and Four Measures

\begin{tabular}{lllllllll}
\hline & \multicolumn{9}{l}{ Whole Sample $(N=41)$} & \multicolumn{7}{l}{ Subgroup $(n=30)$} \\
\cline { 2 - 9 } Variable $(\mathrm{k})$ & $M$ & $S D$ & Max. & Min. & $M$ & $S D$ & Max. & Min. \\
\hline Reading & 207.20 & 105.65 & 430 & 80 & 151.00 & 48.68 & 270 & 80 \\
EL & 10.61 & 4.25 & 19 & 3 & 9.20 & 3.86 & 17 & 3 \\
BW & 10.71 & 3.25 & 16 & 3 & 9.60 & 2.96 & 16 & 3 \\
PR & 7.37 & 4.01 & 14 & 0 & 6.13 & 3.79 & 12 & 0 \\
Vocab & 32.83 & 15.63 & 68 & 8 & 26.57 & 11.76 & 55 & 8 \\
\hline
\end{tabular}

Note . Reading $=$ TOEIC Reading $;$ EL $=$ Elision $; \mathrm{BW}=$ Blending Words; $\mathrm{PR}=$ Phoneme Reversal and Vocab $=$ Vocabulary Size.

\subsection{A Comparison between the Whole Sample and the Subgroup in Four Measures}

A direct comparison of their performance clearly indicates that the whole sample, which included both skilled and less-skilled learners, did outperform the subgroup, which consisted of low reading proficiency learners only (see Table 1). The differences are shown in vocabulary size (the former $M=$ $32.83, S D=15.63$; the latter $M=26.57, S D=11.76$ ) as well as all three PA subtests (the former on EL $M=10.61, S D=4.25$; BW $M=10.71, S D=3.25$; and PR $M=7.37, S D=4.01$ versus the latter on EL $M=9.20, S D=3.86$; BW $M=9.60, S D=2.96$; and PR $M=6.13, S D=3.79$ ). The mean scores of the whole 41 participants in these four measures were all higher than those of the subgroup, indicating that the skilled learners indeed performed, on average, better than the less-skilled learners and consequently boosted the mean scores. However, due to the fact that the low reading proficiency participants were a subgroup in the whole sample, no $t$-test was run to compare their mean differences.

\subsection{Relationships among Reading, Vocabulary Size, and Phonological Awareness}

Pearson's correlation analyses were computed to examine the relationships between all measures with reading (see Table 2). Table 2 is diagonally divided from top left to bottom right into two parts. The part above the diagonal line lists the correlation coefficients for the less-skilled learners and the other half is those for the whole sample.

Table 2. Intercorrelations between TOEIC Reading and Four Measures

\begin{tabular}{llllll}
\hline Variable & Reading & EL & BW & PR & Vocab \\
\hline Reading & - & $.50^{* *}$ & .31 & .33 & $.57 * *$ \\
1. EL & $.67 * * *$ & - & $.71 * * *$ & $.74 * * *$ & $.48^{* *}$ \\
2. BW & $.62 * * *$ & $.77 * * *$ & - & $.64 * * *$ & $.40^{*}$ \\
3. PR & $.58^{* * *}$ & $.75^{* * *}$ & $.74 * * *$ & - & .35 \\
4. Vocab & $.76^{* * *}$ & $.67 * * *$ & $.60 * * *$ & $.49 * *$ & - \\
\hline
\end{tabular}

Note . Reading $=$ TOEIC Reading $; \mathrm{EL}=$ Elision $; \mathrm{BW}=$ Blending Words $; \mathrm{PR}=$ Phoneme Reversal $;$ and 
Vocab $=$ Vocabulary Size

Diagonally above are the correlation coefficients for the subgroup $(n=30)$ and diagonally below are those for the whole sample $(N=41)$.

$* * * p<.001, * * p<.01, * p<.05$.

In the whole sample where both skilled and less-skilled learners were included, the results show that the participants' TOEIC reading scores were correlated not only strongly with their vocabulary size $(r$ $=.76, p<.001)$ but also moderately with their phonological processing skills, with correlation coefficients ranging from .58 to $.67, p<.001$ (two-tailed). Given the fact that PA tasks measured an individual's phonological processing skills, the result indicates a consistent correlational pattern in the mixed-ability group. However, in the subgroup, no consistent correlational association was found. Reading scores were not correlated with all four measures but only with EL $(r=.50, p<.01)$ and Vocab Size $(r=.57, p=.001)$, both two-tailed. Results with slight differences were obtained for the whole sample and the subgroup.

\subsection{Significance and Variance Accounted for by Four Measures in Reading}

Multiple regressions were conducted first, with TOEIC Reading scores as the dependent variable and the other four measures as independent variables. A summary of multiple regression analyses determining predictors of TOEIC Reading scores is presented in Table 3.

Table 3. Multiple Regression Analyses Determining Predictors of TOEIC Reading Scores

\begin{tabular}{|c|c|c|c|c|c|c|}
\hline \multirow[b]{2}{*}{ Measure } & $B$ & $S E B$ & B & $B$ & $S E B$ & $\beta$ \\
\hline & \multicolumn{3}{|c|}{$(N=41)$} & \multicolumn{3}{|c|}{$(n=30)$} \\
\hline EL & 2.44 & 4.75 & .10 & 5.23 & 3.39 & .42 \\
\hline BW & 2.91 & 5.56 & .09 & -2.01 & 3.75 & -.12 \\
\hline PR & 4.34 & 4.34 & .17 & -.67 & 3.08 & -.05 \\
\hline Vocab & 3.78 & .94 & $.94 * * *$ & 1.79 & .74 & $.43 *$ \\
\hline
\end{tabular}

Note . Reading $=$ TOEIC Reading; $\mathrm{EL}=$ Elision $; \mathrm{BW}=$ Blending Words; $\mathrm{PR}=$ Phoneme Reversal ; and Vocab $=$ Vocabulary Size .

$B=$ Unstandardized Coefficient, $S E B=$ Standard Errors, and $\beta=$ Standardized coefficient.

$* * * p<.001, * p<.05$.

The combination of four measures significantly predicted the reading scores, $F(4,36)=15.97, p<.001$, and collectively explained $63.9 \%$ of the variance in reading scores in the 41 participants. Similarly, in the low proficiency subgroup, the four measures significantly predicted reading, $F(4,25)=4.11, p$ $<.05$. But in stark contrast, the variance accounted for by the four measures dropped drastically to $39.7 \%$ in the 30 less-skilled learners. In the whole sample and the subgroup, only vocabulary size 
significantly predicted TOEIC reading scores $(\beta=.94, p<.001$ in 41 participants and $\beta=.43, p<.05$ in 30 participants).

From the previous analyses, it is obvious that vocabulary size was a significant contributor to reading scores; consequently, Vocab was always entered first in hierarchical regressions analyses, in an attempt to probe whether any of the three PA measures made additional contribution to TOEIC Reading after the variance accounted for by vocabulary knowledge was controlled for (see Table 4).

Table 4. Summary of Unique Contribution Made by PA Tasks to TOEIC Reading Scores

\begin{tabular}{|c|c|c|c|c|c|c|c|c|c|}
\hline Variable & $R^{2}$ & $\Delta R^{2}$ & $F$-ratio & B & \multirow{2}{*}{$\begin{array}{l}\text { Variable } \\
\text { Step }\end{array}$} & $R^{2}$ & $\Delta R^{2}$ & $F$-ratio & B \\
\hline Step & \multicolumn{4}{|c|}{$(N=41)$} & & \multicolumn{4}{|c|}{$(n=30)$} \\
\hline 1. Vocab & .58 & .58 & $52.79 * * *$ & $.76 * * *$ & 1. Vocab & .32 & .32 & $13.14 * *$ & $.57 * *$ \\
\hline 2. $1+\mathbf{E L}$ & .62 & .05 & $30.98 * * *$ & $.29 *$ & 2. $1+\mathbf{E L}$ & .39 & .07 & $8.50 * *$ & .30 \\
\hline 3. $2+\mathrm{PR}$ & .64 & .01 & $21.62 * * *$ & .20 & 3. $2+\mathrm{BW}$ & .40 & .01 & $5.67 * *$ & -.13 \\
\hline 4. $3+\mathrm{BW}$ & .64 & .00 & $15.97 * * *$ & .09 & 4. $3+\mathrm{PR}$ & .40 & .00 & $4.11 *$ & -.05 \\
\hline 2. $1+\mathbf{B W}$ & .62 & .04 & $30.76 * * *$ & $.26^{*}$ & 2. $1+\mathrm{BW}$ & .33 & .01 & $6.59 * *$ & .10 \\
\hline 3. $2+\mathrm{PR}$ & .64 & .02 & $21.63 * * *$ & .20 & 3. $2+\mathbf{E L}$ & .40 & .07 & $5.67 * *$ & .39 \\
\hline 4. $3+\mathrm{EL}$ & .64 & .00 & $15.97 * * *$ & .10 & 4. $3+\mathrm{PR}$ & .40 & .00 & $4.11 *$ & -.05 \\
\hline 2. $1+\mathbf{P R}$ & .63 & .05 & $32.55 * * *$ & $.27 *$ & 2. $1+\mathrm{PR}$ & .34 & .02 & $6.92 * *$ & .15 \\
\hline 3. $2+\mathrm{EL}$ & .64 & .01 & $21.62 * * *$ & .13 & 3. $2+\mathbf{E L}$ & .39 & .05 & $5.53 * *$ & .36 \\
\hline 4. $3+\mathrm{BW}$ & .64 & .00 & $15.97 * * *$ & .09 & 4. $3+\mathrm{BW}$ & .40 & .01 & $4.11 *$ & -.12 \\
\hline
\end{tabular}

Note . Reading $=$ TOEIC Reading; EL $=$ Elision; $\mathrm{BW}=$ Blending Words; $\mathrm{PR}=$ Phoneme Reversal $;$ and Vocab $=$ Vocabulary Size.

In Step 3, after a $2^{\text {nd }} \mathrm{PA}$ subtest was added, only the equations with a significant $F$-ratio are listed. $* * * p<.001, * * p<.01, * p<.05$.

The analyses reveal that, in the whole sample, Vocab alone explained 58\% of the variance in TOEIC reading scores, $F(1,39)=52.79, p<.001$, and was the best predictor $(B=.76, p<.001)$. But when one of the three PA subtests was entered next into different models, EL still accounted for significant 5\%, BW 4\%, and PR 5\% of the variance separately in Step 2 . The $\beta$ weights $(\beta=.29$ for EL, $\beta=.26$ for BW, and $B=.27$ for PR; $p<.05$ ) also reveal that Vocab in Step 1 plus whichever PA task entered in Step 2 were significant for predicting TOEIC reading scores in the whole sample of participants. However, while a $2^{\text {nd }}$ PA task was entered in Step 3, each of them explained, at most, $2 \%$ of the variance and none of the $B$ weights in Step 3 was significant, indicating that both vocabulary and either one PA measure were valid predictors of TOEIC reading for the whole sample, on the one hand. On the other hand, types of PA measures did not seem to matter to the whole sample because whichever PA task was entered in Step 2 accounted for a similar amount of variance in reading. 
Parallel hierarchical regressions were next conducted for the low reading proficiency subgroup. Vocab was entered first and explained $32 \%$ of the variance in TOEIC reading scores, $F(1,28)=13.14, p<.01$. Similarly, vocabulary size was significant in predicting TOEIC reading scores in the less-skilled learners $(\beta=.57, p<.01)$. When the three PA subtest scores were entered in Step 2 into the equation after Vocab, each still made an additional contribution: $7 \%$ of the variance by EL, $1 \%$ by BW, and $2 \%$ by PR separately in different models. But intriguingly, when BW and PR were entered after Vocab, they explained $2 \%$ of the variance at most but accounted for little variance in most cases in fact. EL was the only exceptional PA subtest which still explained $5 \%$ to $7 \%$ of the variance in TOEIC reading scores after vocabulary size was accounted for. However, despite its contribution, EL was not a significant predictor. For the low proficiency group, vocabulary was the only valid predictor of TOEIC reading scores.

From the results, it is obvious that vocabulary was a significant predictor of reading ability to both low proficiency learners and a mixed-ability group. The variance explained by vocabulary in reading increased when the sample included not only less-skilled but also skilled learners. However, in contrast to the contribution made by EL solely to reading in the low proficiency subgroup, the three PA subtests did not differ so much from each other to the whole sample probably because the addition of the skilled learners to the sample has mediated their phonological awareness in general.

\section{Discussion}

The 41 participants in the present study were a mixed-ability sample which included 30 less-skilled and 11 skilled L2 learners. Even though the number of skilled learners was fewer than half of that of the less-skilled learners, the mean TOEIC Reading score of the whole sample increased by one third of that of the subgroup. It was a big increase, given that it was a small number of skilled learners against a majority of less-skilled learners. The big contrast in their reading proficiency was similarly found in the vocabulary knowledge and the three phonological awareness measures. The mean scores of the four measures for the whole sample were all higher than those of the subgroup, indicating that the skilled learners all performed comparatively better than the less-skilled learners and consequently boosted the mean scores for the whole sample.

\subsection{Correlations among Reading Comprehension, Vocabulary Size, and Phonological Awareness}

Despite a smaller and a larger vocabulary size for the subgroup and the whole sample respectively, positive correlations were consistently obtained between vocabulary and TOEIC Reading scores. The result clearly indicates the close association between vocabulary and reading comprehension in L2 learners, consistent with findings in previous research (Grant et al., 2011; Pasquarella et al., 2012). The vocabulary size of the whole sample was correlated with their reading scores, suggesting that the larger vocabulary size, the higher reading scores, or vice versa. The same pattern was also observed within the low reading proficiency subgroup. In other words, the results lend support to previous research that vocabulary knowledge might change systematically as the language levels of learners improve (Milton 
\& Alexiou, 2009) and that vocabulary does matter in text comprehension (Nation, 2006; Yamashita, 2013).

The relationship between reading comprehension and phonological awareness was, however, different in the whole sample and the subgroup. In the former, TOEIC reading scores were positively and moderately correlated with all three PA measures, consistent with previous research (Hannon, 2012; Li et al., 2012). Nevertheless, in the subgroup, TOEIC reading scores were significantly correlated with Elision but not with the other two PA measures. Even though it is true that phonological awareness is critical to learning alphabetic languages, there might be a difference in the measure types. When the three PA measures were administered to the participants, it was apparent that Phoneme Reversal was the most challenging, as was shown by its lowest mean score. It is true that the participants had to rely on their knowledge of phonemes in all three measures. However, a bigger memory load might have occurred when participants had to memorize and sequence a string of phonemes-sometimes up to seven phonemes at most-into a word in the Blending Words task. The memory load became heaviest in the PR task because participants had to segment a string of phonemes in a nonword before reversing and combining them into a word. When the two tasks were so demanding, the low proficiency learners could have had problems coping up, which might have explained a lack of association between reading and the two PA tasks. In turn, EL might have been a more proper task to assess L2 learners' phonological awareness, compared to BW and PR.

\subsection{Contributions Made by Vocabulary and Phonological Awareness Measures}

From the multiple regression analyses, it was found that almost $64 \%$ of the variance in TOEIC reading scores was explained by the four measures in the whole sample, in contrast to nearly $40 \%$ in the subgroup. When the hierarchical regression analyses were further conducted to examine unique variance made by each measure, it was revealed that vocabulary explained $58 \%$ of the variance in the former and $32 \%$ in the latter. In addition, vocabulary size was the only significant predictor of the participants' TOEIC reading scores, highlighting the essentiality of vocabulary knowledge in reading (Nation, 2006).

The suggestion that vocabulary size be used as a useful indicator to place L2 learners at an appropriate proficiency level (Milton \& Alexiou, 2009; Milton et al., 2010) might serve as the best explanation. It is commonly true that the more words a learner knows the more proficient the learner usually is. It is especially true to L2 learners (Grant et al., 2011; Li et al., 2012; Pasquarella et al., 2012; Yamashita, 2013). While phonological awareness is critical to learning alphabetic languages, it does not make direct contribution if learners do not know the meaning of the word represented by a string of phonemes (Yoshikawa \& Yamashita, 2014). In other words, efficiency in accessing word meanings more directly assisted learners in reading comprehension and vocabulary size consequently was a more valid predictor.

On the other hand, none of the three PA measures was found to be a significant predictor after the variance made by vocabulary was controlled for, despite the fact that they did make unique contribution 
to TOEIC reading scores. The finding confirms that phonological awareness indeed contributed to reading ability (Clark et al., 2012; Scarborough et al., 2013). However, different results on PA were obtained for the whole sample and the subgroup. It was revealed that different PA measures did not seem to make a difference to the whole sample because whichever PA measure was entered in Step 2, it accounted for additional $4 \%$ to $5 \%$ of the variance in reading. In the subgroup, however, only EL made more additional contribution, ranging from $5 \%$ to $7 \%$, to reading comprehension. The fact that EL seemed to have explained more variance in reading in the subgroup might be accounted for by the relatively poorer performance of the less-skilled learners on BW and PR. When tasks were too difficult, they could not distinguish good from poor learners and might thus make no contribution. In addition, EL might have served as a more adequate measure than BW to assess phonological awareness of L2 learners because only EL accounted for unique variance but not BW, given the fact that the less-skilled learners in fact scored comparably on the two tasks.

\section{Conclusion}

Divided by their reading scores in an internationally standardized test, skilled learners were found to be superior to less-skilled learners in performance on vocabulary knowledge and phonological processing skills. Among the measures, both vocabulary size and EL were consistently associated with reading comprehension, confirming the connection among the three. While vocabulary size was the only significant predictor of reading ability, phonological awareness-EL in particular-also explained additional variance.

Manipulation and analysis of the sound structure of spoken English, i.e., phonological awareness, is critical to L2 learners (Hu, 2013; Li et al., 2012). When short of the necessary backup in literacy development, some L2 learners were even identified as having difficulties in learning to read in English (Harrison \& Krol, 2007). On the other hand, vocabulary size is suggested to be associated with language proficiency levels indexed by standardized language tests (Milton et al., 2010). Despite a small number, the skilled learners recruited for the present study were at least at Intermediate Level. Their vocabulary knowledge had certainly assisted them in comprehending texts. Taken together, good phonological awareness might have helped the skilled learners in word recognition and word knowledge, which in turn assisted their text comprehension. In contrast, the less-skilled learners were less proficient in reading, which could have been attributed to a smaller vocabulary size and poorer phonological processing skills.

For future research, more skilled learners should be recruited to make possible a direct comparison with the less-skilled learners. In addition, phonological memory should be included to assess the participants' capacity of memory load since phonological memory might have an effect on phonological representations (Archibald \& Gathercole, 2007). 


\section{References}

Anthony, J. L., Williams, J. M., McDonald, R., \& Francis, D. J. (2007). Phonological processing and emergent literacy in younger and older preschool children. Annals of Dyslexia, 57(2), 113-137. http://dx.doi.org/10.1007/s11881-007-0008-8

Archibald, L. M. D., \& Gathercole, S. E. (2007). Nonword repetition and serial recall: Equivalent measures of verbal short-term memory? Applied Psycholinguistics, 28, 587-606. http://dx.doi.org/10.1017/S0142716407070324

Bowey, J. A. (2001). Nonword repetition and young children's receptive vocabulary: A longitudinal study. Applied Psycholinguistics, 22, 441-469.

Breznitz, Z. (2001). The determinants of reading fluency: A comparison of dyslexic and average readers. In M. Wolf (Ed.), Dyslexia, fluency, and the brain. Austin, Texas: Pro-Ed, Inc.

Cheung, H., Chen, H.-C., Lai, C. Y., Wong, O. C., \& Hills, M. (2001). The development of phonological awareness: Effects of spoken language experience and orthography. Cognition, 81, 227-241.

Clark, N. B., McRoberts, G. W., van Dyke, J. A., Shankweiler, D. P., \& Braze, D. (2012). Immediate memory for pseudowords and phonological awareness are associated in adults and pre-reading $\begin{array}{lllll}\text { children. } \quad \text { Clinical } & \text { Linguistics }\end{array}$ http://dx.doi.org/10.3109/02699206.2012.673045

Council of Europe. (2001). Common European framework of reference for languages: Learning, teaching, assessment. Cambridge: Cambridge University Press.

Durgunoglu, A. Y., \& Öney, B. (2002). Phonological awareness in literacy acquisition: It's not only for children. Scientific Studies of Reading, 6, 245-266.

Educational Testing Service. (2012). Test and score data summary for TOEFL iBT tests and TOEFL PBT tests: January 2011-December 2011 test data. Retrieved from http://www.ets.org/s/toefl/pdf/94227_unlweb.pdf

Ehri, L. C. (2005). Learning to read words: Theory, findings, and issues. Scientific Studies of Reading, 9(2), 167-188. http://dx.doi.org/10.1207/s1532799xssr0902_4

Grabe, W. (2009). Reading in a second language: Moving from theory to practice. N.Y.: CUP.

Grant, A., Gottardo, A., \& Geva, E. (2011). How is language acquisition background related to the development of reading comprehension in students learning to speak English as a second language? Learning Disabilities: Research and Practice, 26(2), 67-83.

Hannon, B. (2012). Understanding the relative contributions of lower-level word processes, higher-level processes, and working memory to reading comprehension performance in proficient adult readers. Reading Research Quarterly, 47(2), 125-152. http://dx.doi.org/10.1002/RRQ.013

Harrison, G. L., \& Krol, L. (2007). Relationship between L1 and L2 word-level reading and phonological processing in adults learning English as a second language. Journal of Research in Reading, 30(4), 379-393. http://dx.doi.org/10.1111/j.1467-9817.2007.00351.x 
Hu, C.-F. (2013). Predictors of reading in children with Chinese as a first language: A developmental and cross-linguistic perspective. Reading \& Writing, 26(2), 163-187. http://dx.doi.org/10.1007/s11145-012-9360-0

Hulslander, J., Olson, R. K., Willcutt, E. G., \& Wadsworth, S. J. (2010). Longitudinal stability of reading-related skills and their prediction of reading development. Scientific Studies of Reading, 14(2), 111-136. http://dx.doi.org/10.1080/10888431003604058.

Kintsch, W., \& Rawson, K. A. (2005). Comprehension. In M. J. Snowling, \& C. Hulme (Eds.), The science of reading: A handbook (pp. 209-226). Oxford: Blackwell.

Li, T., McBride-Chang, C., Wong, A., \& Shu, H. (2012). Longitudinal predictors of spelling and reading comprehension in Chinese as an L1 and English as an L2 in Hong Kong Chinese children. Journal of Educational Psychology, 104(2), 286-301.

Masoura, E., \& Gathercole, S. E. (2005). Contrasting contributions of phonological short-term memory and long-term knowledge to vocabulary learning in foreign language. Memory, 13(3/4), 422-429.

Milton, J., \& Alexiou, T. (2009). Vocabulary size and the Common European Framework of Reference for languages. In B. Richards, H. M. Daller, D. D. Malvern, P. Meara, J. Milton, \& J. Treffers-Dallers (Eds.), Vocabulary studies in first and second language acquisition (pp. 194-211). Hampshire, England: Palgrave Macmillan.

Milton, J., Wade, J., \& Hopkins, N. (2010). Aural word recognition and oral competence in a foreign language. In R. Chacón-Beltrán, C. Abello-Contesse, \& M. Torreblanca-López (Eds.), Further insights into non-native vocabulary teaching and learning (pp. 83-97). Buffalo: Multingual Matters.

Nation, I. S. P. (2006). How large a vocabulary is needed for reading and listening? The Canadian Modern Language Review, 63(1), 59-82.

Nation, P., \& Beglar, D. (2007) Vocab Size Test, BNC Version (1-14k). Retrieved from http://www.lextutor.ca/tests/levels/recognition/1_14k/

Pasquarella, A., Chen, X., Lam, K., Luo, Y. C., \& Ramirez, G. (2011). Cross-language transfer of morphological awareness in Chinese-English bilinguals. Journal of Research in Reading, 34(1), 23-42. http://dx.doi.org/10.1111/j.1467-9817.2010.01484.x

Pasquarella, A., Gottardo, A., \& Grant, A. (2012). Comparing factors related to reading comprehension in adolescents who speak English as a first (L1) or second (L2) language. Scientific Studies of Reading, 16(6), 475-503. http://dx.doi.org/10.1080/10888438.2011.593066

Sabatini, J. P., Sawaki, Y., Shore, J. R., \& Scarborough, H. S. (2010). Relationships among reading skills of adults with low literacy. Journal of Learning Disabilities, 43(2), 122-138.

Scarborough, H. S., Sabatini, J. P., Shore, J., Cutting, L. E., Pugh, K., \& Katz, L. (2013). Meaningful reading gains by adult literacy learners. Reading and Writing, 26, 593-613. http://dx.doi.org/10.1007/s11145-012-9385-4

Wagner, R. K., Torgesen, J. K., \& Rashotte, C. A. (1999). Comprehensive test of phonological 
processing. Austin, TX: Pro-Ed.

Yaghoub-Zadeh, Z., Farnia, F., \& Geva, E. (2012). Toward modeling reading comprehension and reading fluency in English language learners. Reading \& Writing, 25(1), 163-187. http://dx.doi.org/10.1007/s11145-010-9252-0

Yamashita, J. (2013). Word recognition subcomponents and passage level reading in a foreign language. Reading in a Foreign Language, 25(1), 52-71.

Yoshikawa, L., \& Yamashita, J. (2014). Phonemic awareness and reading comprehension among Japanese adult learners of English. Open Journal of Modern Linguistics, 4, 471-480. http://dx.doi.org/10.4236/ojml.2014.44039

Yu, M. N. (2003). A survey report on current English proficiency levels of college students in Taiwan. Taipei: Global Education Association in Taiwan.

\section{Note}

Note 1. L2 and EFL are used interchangeably in the study. 